\title{
Dietary linoleic acid and the plasma phospholipids of the rabbit
}

\author{
By J. H. MOORE AND R. C. NOBLE \\ Hannah Dairy Research Institute, Ayr \\ (Received 26 November 1968-Accepted I4 March 1969)
}

\begin{abstract}
1. Groups of rabbits were given diets containing different proportions of butterfat and maize oil. After the animals had been given the experimental diets for 40 weeks the plasma phospholipids were fractionated and the fatty acid composition of each fraction was determined.

2. Phosphatidyl choline and lysophosphatidyl choline accounted for about 75 and I $2 \%$ respectively of the total plasma phospholipids: phosphatidyl ethanolamine, sphingomyelin and phosphatidyl serine accounted for only about $5.3,5.0$ and $2.6 \%$ respectively. Changes in the linoleic acid content of the diet had little effect on the relative proportions of the individual plasma phospholipids, but there was an over-all decrease in the concentration of total phospholipids in the plasma as the linoleic acid content of the diet was increased from 0.25 to $10.6 \%$.

3. When the diet contained $0.25 \%$ linoleic acid, the linoleic acid:oleic acid ratio in the phosphatidyl choline $(\mathrm{I} \cdot 3)$ was similar to that in the phosphatidyl ethanolamine $(\mathrm{I} \cdot 2)$, but as the linoleic acid content of the diet was increased to $10.6 \%$ the linoleic acid:oleic acid ratio in the phosphatidyl choline increased to 4.8 , whereas that in the phosphatidyl ethanolamine increased only to $\mathbf{2 \cdot 2}$. Increases in the linoleic acid content of the diet resulted also in increases in the linoleic acid:oleic acid ratios in the phosphatidyl serine, lysophosphatidyl choline and sphingomyelin.

4. When the linoleic acid content of the diet was increased, the stearic acid:palmitic acid ratio in the phosphatidyl choline increased, whereas it decreased in the phosphatidyl ethanolamine and remained relatively unaltered in the phosphatidyl serine. The stearic acid contents of the lysophosphatidyl choline and sphingomyelin were unaltered by dietary treatments, but the palmitic acid content of these two phospholipids decreased as the linoleic acid content of the diet increased.
\end{abstract}

5. The results are discussed in terms of the metabolic relationships that exist between the various phospholipids.

In a previous investigation (Moore, Williams $\&$ Westgarth, 1965), it was found that when the linoleic acid content of the diet of rabbits was increased the linoleic acid and stearic acid contents of the plasma phosphatidyl choline were increased whereas the contents of palmitic and oleic acids were decreased. Moreover, in the plasma phosphatidyl choline, significant positive rectilinear relationships were found between the concentration of stearic acid in the $\alpha$-position and the concentration of linoleic acid in the $\beta$-position and between the concentration of palmitic acid in the $\alpha$-position and the concentration of oleic acid in the $\beta$-position. It was concluded that the level of linoleic acid in the diet exerts a direct effect on the composition of the fatty acids occupying the $\beta$-position and an indirect effect on the composition of the fatty acids occupying the $\alpha$-position of the plasma phosphatidyl choline. In the study now reported, the fatty acid compositions of all the various plasma phospholipids have been determined in groups of rabbits given diets that contained between 0.25 and $10.6 \%$ linoleic acid. 


\section{EXPERIMENTAL}

\section{Rabbits, diets and procedure}

A detailed account of the rabbits, diets and experimental procedures has been given by Moore (I969). Briefly, one hundred and five New Zealand White male rabbits were randomly divided into seven groups of fifteen each and the animals were housed in individual cages. Throughout the experiment, food and water were given ad lib. The basal, low-fat diet consisted (parts by weight) of wheat starch $16 \cdot 3$, sucrose $10 \cdot 0$, casein $25^{\circ}$, Solkafloc (grade $\mathrm{BW}_{40}{ }^{\circ}$; Johnsen, Jorgensen and Wettre Ltd, London, $\mathrm{EC}_{4}$ ) I9, methyl cellulose (Celacol M45; J. M. Steel and Co Ltd, London, WC 2) $\mathrm{I} \cdot 0$, potassium acetate 2.5 , magnesium oxide 0.5 , sodium chloride 0.7 , choline chloride 0.5 , salt mixture 4.0 and vitamin mixture 0.5 , making 80 parts in all. The compositions of the salt and vitamin mixtures have been given by Moore \& Williams (r964a). To 80 parts of this low-fat basal diet were added different proportions of maize oil and butterfat for each dietary treatment as indicated in Table $\mathrm{I}$. The butterfat was prepared as described by Moore \& Williams ( $1964 a$ ). After 40 weeks on the experimental diets, a sample of blood was taken from the marginal ear vein of each rabbit. The blood samples were collected in heparinized tubes.

\section{Methods of analysis}

The lipids were extracted from the plasma samples by the method of Nelson \& Freeman (1959). The total phospholipid content of each lipid extract was determined as described previously (Moore \& Doran, 1962; Moore \& Williams, I964 $b$ ). The plasma lipid extracts were then combined so that there were three pooled groups for each dietary treatment, and each pooled group contained the plasma lipid extracts obtained from four or five rabbits. (Certain of the rabbits died during the experiment.) The plasma phospholipids in each pooled sample were fractionated and analysed by the methods described in detail by Noble \& Moore ( 1965$)$. The fatty acid compositions of the various phospholipid fractions were determined as described by Moore $\&$ Williams (1963, 1964c) except that the gas-liquid chromatography was carried out with an instrument fitted with dual-flame ionization detectors (Perkin-Elmer Ltd, Beaconsfield, Bucks). The fatty acid compositions of the experimental diets were determined as described by Moore \& Williams (1963).

\section{RESULTS}

The results given in Table I show that the successive replacement of butterfat by maize oil in the diet resulted in an over-all decrease in the concentration of total phospholipids in the plasma. However, the proportions of the individual phospholipids in the total plasma phospholipids were largely unaffected by dietary treatment.

The fatty acid compositions of the various phospholipid fractions in the plasma of the experimental rabbits are given in Tables 2 and 3 . In these tables, values are given for the four major constituent fatty acids only. Palmitic, stearic, oleic and linoleic acids together accounted for $97,94,95,96$ and $95 \%$ of the total fatty acids in the 
phosphatidyl choline, phosphatidyl ethanolamine, phosphatidyl serine, lysophosphatidyl choline and sphingomyelin respectively. Small concentrations of myristic, palmitoleic and arachidonic acids largely accounted for the remainder. The concentrations of these minor constituent acids did not vary with dietary treatment. The fact that the arachidonic acid content of the various plasma phospholipids was not affected by the linoleic acid content of the diet is in agreement with previous findings with rabbits. In the cholesteryl esters, triglycerides and total phospholipids of rabbit liver and plasma, Moore \& Williams (1963, 1964 $d, 1965,1966)$ found low concentrations

Table I. Contents of maize oil, butterfat and linoleic acid in the experimental diets, the concentration of total phospholipid in the plasma of the rabbits and the concentrations of individual plasma phospholipids expressed as percentages of the total plasma phospholipids

\begin{tabular}{|c|c|c|c|c|c|c|c|c|}
\hline & $\underset{\mathbf{I}}{\text { Group }}$ & $\begin{array}{l}\text { Group } \\
\quad 2\end{array}$ & $\begin{array}{l}\text { Group } \\
3\end{array}$ & $\begin{array}{c}\text { Group } \\
4\end{array}$ & $\begin{array}{l}\text { Group } \\
5\end{array}$ & $\underset{6}{\text { Group }}$ & $\begin{array}{l}\text { Group } \\
7\end{array}$ & $\begin{array}{l}\mathrm{SE} \text { of } \\
\text { a mean }\end{array}$ \\
\hline Maize oil content of diet $(\mathrm{g} / \mathrm{I} 00 \mathrm{~g})$ & $\circ$ & 2 & 4 & 6 & 8 & 10 & 20 & - \\
\hline Butterfat content of diet $(\mathrm{g} / \mathrm{r} 00 \mathrm{~g})$ & 20 & 18 & 16 & I 4 & 12 & 10 & $\circ$ & 一 \\
\hline $\begin{array}{l}\text { Linoleic acid content of diet } \\
(\mathrm{g} / \mathrm{I} 00 \mathrm{~g})\end{array}$ & 0.25 & $1 \cdot 27$ & $2 \cdot 32$ & $3 \cdot 36$ & 4.37 & $5 \cdot 44$ & $10 \cdot 6$ & - \\
\hline $\begin{array}{l}\text { Concentration of total } \\
\text { phospholipid in plasma } \\
(\mathrm{mg} / 100 \mathrm{ml})\end{array}$ & 143 & 127 & 116 & 109 & 108 & IIO & $84 \cdot 3$ & $9 \cdot 80$ \\
\hline \multicolumn{9}{|c|}{$\begin{array}{l}\text { Concentrations of individual phospholipids } \\
\text { (g/100 g total plasma phospholipid) }\end{array}$} \\
\hline Phosphatidyl choline & $75^{\circ} 9$ & $76 \cdot 7$ & $72 \cdot 9$ & 74.5 & $74^{\cdot 6}$ & $75 \cdot 6$ & $74 \cdot 2$ & 0.47 \\
\hline Phosphatidyl ethanolamine & $5 \cdot 63$ & 4.55 & $5 \cdot 54$ & $4 \cdot 86$ & $5 \cdot 31$ & $5 \cdot 25$ & $5 \cdot 63$ & $0 \cdot 16$ \\
\hline Phosphatidyl serine & $3 \cdot 84$ & $2 \cdot 37$ & $2 \cdot 83$ & $2: 49$ & $2 \cdot 3 I$ & $2 \cdot 65$ & $2 \cdot 83$ & 0.20 \\
\hline Lysophosphatidyl choline & I I $\cdot 0$ & $9 \cdot 98$ & $13 \cdot 0$ & I2:3 & $13 \cdot 5$ & $12 \cdot 9$ & $12 \cdot 2$ & 0.46 \\
\hline Sphingomyelin & $3 \cdot 64$ & $6 \cdot 45$ & $5 \cdot 74$ & 5.86 & 434 & $3 \cdot 60$ & $5 \cdot 12$ & 0.43 \\
\hline
\end{tabular}

of arachidonic acid that were not increased when the linoleic acid content of the diet was increased. In this respect, the lipid metabolism of the rabbit differs markedly from that of the rat. According to Klein (1957) and Mohrhauer \& Holman (1963) the arachidonic acid content of the liver and plasma lipids of the rat increases when the diet is supplemented with linoleic acid. The possible reasons for these differences in the metabolism of linoleic acid by the rat and rabbit have been discussed by Moore \& Williams ( 1965$)$.

It has now been well established that the phosphatidyl choline, phosphatidyl ethanolamine and phosphatidyl serine obtained from most animal tissues consist mainly, but not exclusively, of molecules with saturated fatty acids occupying the $\alpha$-position and unsaturated fatty acids occupying the $\beta$-position (Hanahan, Brockerhoff \& Barron, I960; Saito \& Hanahan, I962; Privett \& Blank, I963; Moore \& Williams, 1964c). From the results in Table 2 it can be calculated that, irrespective of dietary treatment, the ratios of total unsaturated to total saturated fatty acid in the phosphatidyl choline and phosphatidyl ethanolamine were about $\mathrm{I}_{4} 4$ and $\mathrm{I} \cdot 3$ respectively: this indicated that there must have been a certain proportion of these two diacyl phospholipids with unsaturated fatty acids in both the $\alpha$ - and $\beta$-positions. In contrast, the increase in the linoleic acid content of the diet from 0.25 to $10.6 \%$ brought about an increase in the 


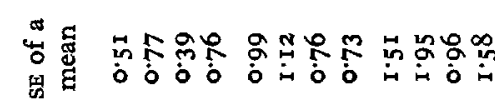

密

8

2

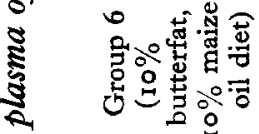

इ

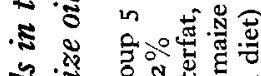

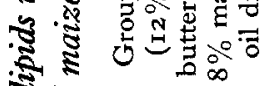

$\infty$

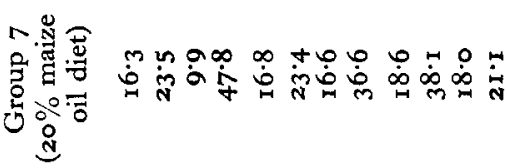

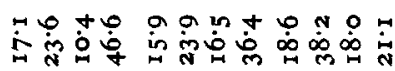

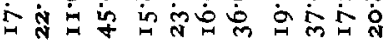

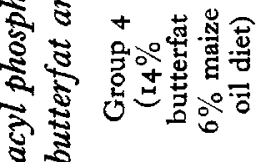

ลัญ ปั

(3)

₹

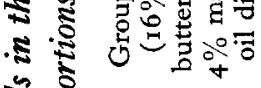

है

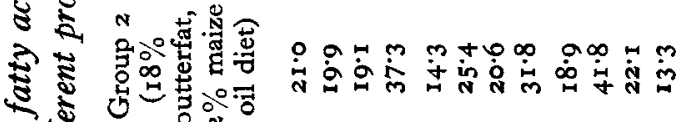

.

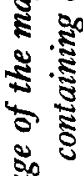

:

है

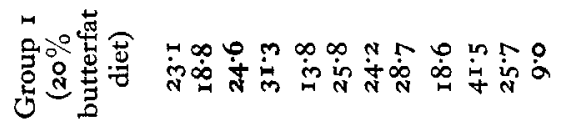

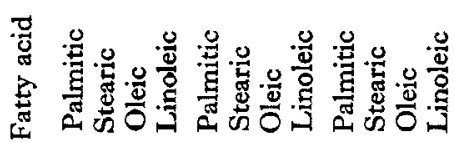

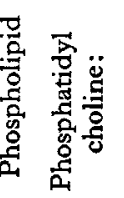

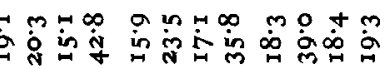

$\log 20$

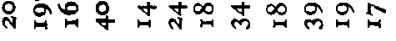

is

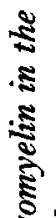

辛.

है

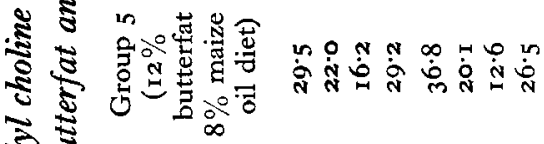

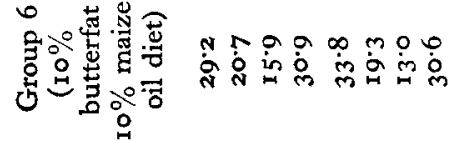

胥票

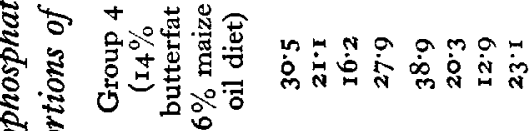

공.

.

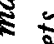

ะ

5

.

So $\frac{\pi}{5}$

है

\&

离

हัँ

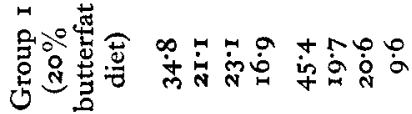

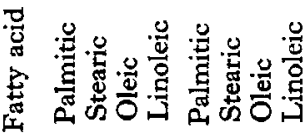

$\dot{0}$

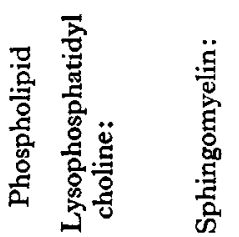


ratio of total unsaturated to total saturated fatty acid in the phosphatidyl serine from 0.58 to 0.69 . These ratios show that in the phosphatidyl serine there must have been a certain proportion of the molecules with saturated fatty acids in both the $\alpha$-and $\beta$-positions. The successive replacement of the dietary butterfat by maize oil resulted in increases in the linoleic acid:oleic acid ratios in all three diacyl phospholipids (Table 2) and it seems reasonable to suppose that these increases were largely the result of replacement of oleic acid by linoleic acid in the $\beta$-positions of these phospholipids. However, for each diacyl phospholipid there was a characteristic pattern of change in the linoleic acid:oleic acid ratio as the linoleic acid content of the diet increased. When the diet contained $0.25 \%$ linoleic acid, the linoleic acid:oleic acid ratio in the phosphatidyl choline $\left(x^{\prime} 3\right)$ was similar to that in the phosphatidyl ethanolamine ( $\mathrm{I} \cdot 2$ ) but, as the linoleic acid content of the diet was increased to $10.6 \%$, the linoleic acid:oleic acid ratio in the phosphatidyl choline increased to $4 \cdot 8$, whereas that in the phosphatidyl ethanolamine increased only to $2 \cdot 2$. The linoleic acid:oleic acid ratio in the plasma phosphatidyl serine of the rabbits given the diet containing $0.25 \%$ linoleic acid was comparatively low $(0.35)$, but there was a marked increase in the ratio to about $I \cdot I$ when the linoleic acid content of the diet was increased to $3.36 \%$. Further increases in the linoleic acid content of the diet appeared to have little effect on the linoleic acid: oleic acid ratio in the phosphatidyl serine. Changes in the butterfat and maize oil content of the diet brought about changes in the stearic acid:palmitic acid ratios in the three diacyl phospholipids (Table 2) and it may be assumed that these changes were largely a reflection of the changes that occurred in the composition of the fatty acids occupying the $\alpha$-positions. There were also characteristic patterns of change in the stearic acid:palmitic acid ratio for each diacyl phospholipid. Thus, when the linoleic acid content of the diet increased from 0.25 to $10.6 \%$, the stearic acid: palmitic acid ratio in the phosphatidyl choline increased from 0.81 to $1 \cdot 4$, but in the phosphatidyl ethanolamine it decreased from $\mathrm{I} \cdot 9$ to $\mathrm{I} \cdot 4$. The changes in dietary treatment appeared to have little effect on the comparatively high stearic acid: palmitic acid ratio $(2 \cdot I)$ in the phosphatidyl serine.

From the results in Table 3 it can be calculated that when the linoleic acid content of the diet was increased from 0.25 to $10.6 \%$ there were also pronounced increases in the linoleic acid:oleic acid ratios in the lysolecithin (from 0.73 to $2 \cdot 3$ ) and sphingomyelin (from 0.48 to 2.7 ); the ratio of total unsaturated to total saturated fatty acid increased from 0.72 to 0.98 in the lysolecithin and from 0.48 to 0.64 in the sphingomyelin. The lysolecithin and sphingomyelin contained similar concentrations of stearic acid (about $20 \%$ ) that were unaltered by changes in dietary treatment. On the other hand, the increase in the linoleic acid content of the diet resulted in decreases in the concentrations of palmitic acid in these two plasma phospholipids.

\section{DISCUSSION}

Phosphatidyl choline accounted for about $75 \%$ of the phospholipids in the plasma of the rabbits. Similar values have been reported for many other species. Thus, phosphatidyl choline has been found to account for between 64 and $83 \%$ of the plasma 
phospholipids of the dog, pig, rat, horse, cow, goat and sheep (Dawson, Hemington $\&$ Lindsay, 1960; Nelson, 1967) and for between 66 and $75 \%$ of the plasma phospholipids of man (Phillips, 1958; Marinetti, Albrecht, Ford \& Stotz, 1959; Dawson et al. 1960; Nelson \& Freeman, 1960; Nelson, 1962; Phillips \& Dodge, 1967). The other two diacyl phospholipids, phosphatidyl ethanolamine and phosphatidyl serine, were relatively minor components and together comprised only about $8 \%$ of the rabbit plasma phospholipids. Other investigators have not determined these two phospholipids separately and the plasma phospholipids of man have been reported to contain between 5.6 and $6.4 \%$ of phosphatidyl ethanolamine plus phosphatidyl serine (Gjone, Berry \& Turner, 1959; Nelson \& Freeman, I960; Nelson, 1962). With respect to the phosphatidyl choline and phosphatidyl ethanolamine contents, the plasma phospholipids of the rabbit are markedly different from those of the turkey, domestic fowl and guinea-pig which contain as much as $22 \%$ phosphatidyl ethanolamine and only about 55\% phosphatidyl choline (Sinclair, I948; Ranney, Entenman \& Chaikoff, 1949; Nelson, 1967). The lysophosphatidyl choline content of rabbit plasma phospholipids appeared to be somewhat greater than that of human plasma phospholipids and considerably greater than that of ruminant plasma phospholipids. Human plasma phospholipids contain between 6 and 9\% lysophosphatidyl choline (Phillips, 1958; Marinetti et al. 1959; Gjone et al. 1959; Phillips \& Dodge, r967), whereas cow and sheep plasma phospholipids contain only about $4 \%$ lysophosphatidyl choline (J. H. Moore and R. C. Noble, unpublished observations). The sphingomyelin content of rabbit plasma phospholipids is much less than that of the plasma phospholipids of many other species. For instance, sphingomyelin accounts for about $20 \%$ of the plasma phospholipids of man (Phillips, 1958; Marinetti et al. 1959; Nelson \& Freeman, 1960; Nelson, 1962; Phillips \& Dodge, 1967) and of the cow and sheep (J. H. Moore and R. C. Noble, unpublished observations).

The pattern of distribution of the two saturated fatty acids in the diacyl phospholipids in rabbit plasma (Table 2) is similar to that found for the diacyl phospholipids in the plasma of man. Phillips \& Dodge (1967) reported that, in human plasma, palmitic acid was the major saturated fatty acid in the phosphatidyl choline, whereas stearic acid was the major saturated acid in the phosphatidyl ethanolamine and phosphatidyl serine. In complete agreement with previous findings (Moore et al. 1965), the results in Table 2 show that, as the linoleic acid content of the diet was increased, the stearic acid:palmitic acid and linoleic acid:oleic acid ratios in the phosphatidyl choline increased. Moore et al. (1965) interpreted these findings as indicating that the increases in the level of dietary linoleic acid resulted in an increase in the proportion of $\alpha$-stearoyl $\beta$-linoleoyl phosphatidyl choline and a decrease in the proportion of $\alpha$-palmitoyl $\beta$-oleoyl phosphatidyl choline in the plasma phospholipids. It is now known that the phosphatidyl choline of rat tissues consists of a number of distinct molecular species in which there are specific pairings of individual saturated fatty acids in the $\alpha$-position with individual unsaturated fatty acids in the $\beta$-position (van Golde, Pieterson \& van Deenen, I968; Kuksis, Marai, Breckenridge, Gornall \& Stachnyk, 1968; Arvidson, 1968a, b). Similar findings have been reported for the phosphatidyl ethanolamine of rat tissues (Arvidson, 1968a). There is also evidence 
that the different molecular species of phosphatidyl choline are derived from different synthetic pathways. Thus, the results of Isozaki, Yamamoto, Amako, Sukai \& Okita (1962) and Lyman, Tinoco, Bouchard, Sheehan, Ostwald \& Miljanich (1967) indicate that in rat liver the phosphatidyl choline containing palmitic and linoleic acids is synthesized by the pathway involving an $\alpha, \beta$-diglyceride and cytidine diphosphate choline as intermediates (Kennedy \& Weiss, r956), whereas the phosphatidyl choline containing stearic and arachidonic acid is synthesized by methylation of phosphatidyl ethanolamine (Bremer, Figard \& Greenberg, I960). It is difficult to know whether these findings with rats may be extrapolated to rabbits in which the tissue phosphatidyl choline contains such a small proportion of molecules with arachidonic acid in the $\beta$-position. Nevertheless, the increase in the stearic acid:palmitic acid ratio in the plasma phosphatidyl choline and the concomitant decrease in the ratio of these two saturated fatty acids in the phosphatidyl ethanolamine (Table 2) would be consistent with a proportional increase in the production of phosphatidyl choline from the methylation of phosphatidyl ethanolamine rich in stearic acid.

Although it has been firmly established that lysophosphatidyl choline, in spite of its haemolytic properties, is a normal constituent of the plasma of man (Phillips, 1958 ; Marinetti et al. 1959; Nelson, 1962; Williams, Kuchmak \& Witter, 1966; Phillips \& Dodge, 1967) and other species (Nelson, 1967), little is known about the metabolic origin of this plasma phospholipid. Since unsaturated fatty acids accounted for between 40 and $48 \%$ of the total fatty acids in the lysophosphatidyl choline (Table 3 ), it seems reasonable to conclude that rabbit plasma contains similar proportions of $\alpha$ - and $\beta$-lysophosphatidyl choline. Tattrie \& Cyr (1963) arrived at similar conclusions with regard to the lysophosphatidyl choline of human and bovine plasma. Williams et al. (1966) and Phillips \& Dodge (I967) have also reported that unsaturated fatty acids comprise up to $40 \%$ of the fatty acids in the lysophosphatidyl choline of human plasma. As suggested by Stein \& Stein (I966), the plasma lysophosphatidyl choline might result from the plasma transesterification reaction in which a proportion of the plasma cholesterol is esterified with the fatty acid derived from the $\beta$-position of the plasma phosphatidyl choline (Glomset, 1968). However, the lysophosphatidyl choline so produced would be the $\alpha$-isomer and should therefore contain virtually no unsaturated fatty acids. It seems more likely that the plasma lysophosphatidyl choline is derived from the liver, homogenates of which have been shown to catalyse the hydrolysis of phosphatidyl choline with the formation of the two structural isomers of lysophosphatidyl choline (van den Bosch \& van Deenen, 1965; Waite \& van Deenen I967).

The experimental rabbits were housed at the National Institute for Research in Dairying, Shinfield, and the authors are grateful to the Director, Professor Sir Ronald Baskett, for his co-operation. The authors thank Miss A. Wallace for skilled technical assistance. This study was supported by a grant from the Butter Information Council. 


\section{REFERENCES}

Arvidson, G. A. E. (rg68a). Eur. F. Biochem. 4, 478.

Arvidson, G. A. E. (1968b). Eur. F. Biochem. 5, 415.

Bremer, J., Figard, P. H. \& Greenberg, D. M. (1960). Biochim. biophys. Acta 43, 477.

Dawson, R. M. C., Hemington, N. \& Lindsay, D. B. (1960). Biochem. F. 77, 226.

Gjone, E., Berry, J. F. \& Turner, D. A. (1959). F. Lipid Res. 1, 66.

Glomset, J. A. (1968). F. Lipid Res. 9, 155.

Hanahan, D. J., Brockerhoff, H. \& Barron, E. J. (1960). F. biol. Chem. 235, 1917.

Isozaki, M., Yamamoto, A., Amako, T., Sukai, Y. \& Okita, H. (1962). Med. F. Osaka Univ. $12,285$.

Kennedy, E. P. \& Weiss, S. B. (1956). F. biol. Chem. 222, 193.

Klein, P. D. (1957). Archs Biochem. Biophys. 72, 238.

Kuksis, A., Marai, L., Breckenridge, W. C., Gornall, D. A. \& Stachnyk, O. (1968). Can. Y. Physiol. Pharmacol. 46, 511 .

Lyman, R. L., Tinoco, J., Bouchard, P., Sheehan, G., Ostwald, R. \& Miljanich, P. (1967). Biochim. biophys. Acta ז37, 107.

Marinetti, G. V., Albrecht, M., Ford, T. \& Stotz, E. (1959). Biochim. biophys. Acta 36, 4.

Mohrhauer, H. \& Holman, R. T. (1963). F. Lipid Res. 4, I5I.

Moore, J. H. (1969). Br. Y. Nutr. 23, 125.

Moore, J. H. \& Doran, B. M. (I962). Biochem. F. 84, 506.

Moore, J. H. \& Williams, D. L. (1963). Can. F. Biochem. Physiol. 41, 1821.

Moore, J. H. \& Williams, D. L. (1964a). Br. F. Nutr. 18, 253.

Moore, J. H. \& Williams, D. L. (1964b). Br. F. Nutr, 18, 431.

Moore, J. H. \& Williams, D. L. (I964c). Biochim. biophys. Acta 84, 41.

Moore, J. H. \& Williams, D. L. (1964d). Br. F. Nutr. 18, 603.

Moore, J. H. \& Williams, D. L. (1965). Br. $\mathscr{~}$. Nutr. 19, 407.

Moore, J. H. \& Williams, D. L. (1966). Br. F. Nutr. 20, 79.

Moore, J. H., Williams, D. L. \& Westgarth, D. R. (1965). Biochim. biophys. Acta I06, 145.

Nelson, G. J. (1962). F. Lipid Res. 3, 7r.

Nelson, G. J. (1967). Lipids 2, 323.

Nelson, G. J. \& Freeman, N. K. (1959). F. biol. Chem. 234, 1375.

Nelson, G. J. \& Freeman, N. K. (1960). F. biol. Chem. 235, 578.

Noble, R. C. \& Moore, J. H. (1965). Can. F. Biochem. Physiol. 43, 1677.

Phillips, G. B. (1958). Biochim. biophys. Acta 29, 594.

Phillips, G. B. \& Dodge, J. T. (1967). F. Lipid Res. 8, 676.

Privett, O. S. \& Blank, M. L. (1963). F. Am. Oil Chem. Soc. 40, 7o.

Ranney, R. E., Entenman, C. \& Chaikoff, I. L. (I949). F. biol. Chem. 180, 307.

Saito, K. \& Hanahan, D. J. (1962). Biochemistry, Easton I, 521.

Sinclair, R. G. (1948). F. biol. Chem. 174, 343 .

Stein, Y. \& Stein, O. (х 966). Biochim. biophys. Acta х $6,95$.

Tattrie, N. H. \& Cyr, R. (1963). Biochim. biophys. Acta 7o, 693.

van den Bosch, H. \& van Deenen, L. L. M. (1965). Biochim. biophys. Acta 106, 326.

van Golde, L. M. G., Pieterson, W. A. \& van Deenen, L. L. M. (1968). Biochim. biophys. Acta 152, 84. Waite, M. \& van Deenen, L. L. M. (1967). Biochim. biophys. Acta 137, 498.

Williams, J. H., Kuchmak, M. \& Witter, R. F. (1966). Lipids I, 89. 